\title{
A SÍNDROME DE TURNER EM ODONTOLOGIA
}

\author{
The Turner's Syndrome in Odontology
}

Marcela Lima Cardoso SELOW'; Iran VIEIRA'; Andressa Mendes FIGUEIREDO²; Marcelo Rioiti MIYAKR

\section{RESUMO}

A Síndrome de Turner (ST) foi descrita primeiramente por Ulrich e Turner em 1938, e representa uma das mais freqüentes aberrações cromossômicas. É caracterizada pela presença de apenas um cromossomo $\mathrm{X}$ funcional. $\mathrm{O}$ outro cromossomo sexual é inexistente ou anormal (LOPEZ et al., 2002)5. O cariótipo mais comum é o $45, X$, que está presente em $40 \%$ a $60 \%$ das pacientes com esta patologia. As características dessa síndrome são disgenesia gonadal, atraso no desenvolvimento puberal, amenorréia primária, esterilidade, peito largo, pescoço curto e/ou alado, cubitus valgus, mordida aberta anterior, diminuição do comprimento das raízes de pré-molares, entre outras. O presente artigo trata-se de um relato de caso clínico de uma paciente com Síndrome de Turner atendida na Disciplina de Semiologia Aplicada na Universidade Federal do Paraná e das implicações desta síndrome sobre a saúde bucal e, também, a importância de um tratamento profilático adequado.

Palavras-chave: Odontologia; Síndrome de Turner.

\section{ABSTRACT}

The Turner's Syndrome (TS) was firstly described by Ulrich and Turner on 1938, and represents one of the most frequently chromosomic aberrations. It's characterized by the presence of only one functional $X$ chromosome. The other

${ }^{1}$ Professores da Disciplina de Semiologia Aplicada da Universidade Federal do Paraná - UFPR.

${ }^{2}$ Acadêmicos do Curso de Odontologia da UFPR. 
sexual chromosome doesn't exist or is abnormal (Lopez et al., 2002) ${ }^{5}$. The most common kariotype is the $45, \mathrm{X}$, which is present in $40 \%$ to $60 \%$ of the patients with this pathology. This syndrome characteristic are gonadal disgenesis, puberal development delay, primary amenorrhea, sterility, wide chest, short and/or winged neck, cubitus valgus, anterior open bite, reduction of the length of pre-molar roots, among others. The present article is about a clinical case of a patient with Turner's Syndrome, examined at the Applied Stomatology lecture, at Universidade Federal do Paraná, and the implications of this syndrome on bucal health and also the importance of na adjusted prophylactic treatment.

Keywords: Dentistry; Turner's Svndrome.

\section{INTRODUÇÃO}

A Síndrome de Turner (ST) é uma síndrome complexa. Também chamada de síndrome do X0 ou Síndrome de BonnevieUlrich. Descrita, primeiramente, por Ulrich e Turner em 1938, representa uma das mais freqüentes aberrações cromossômicas. É caracterizada pela presença de apenas ${ }^{1}$ cromossomo $X$ funcional. $O$ outro cromossomo sexual é inexistente ou anormal (LOPEZ et al., 2002) ${ }^{5}$. O cariótipo mais comum é o $45, X$, que está presente em $40 \%$ a $60 \%$ das pacientes com a ST. O isocromossomo Xq foi observado em $12 \%$ a $20 \%$ dos casos com a duplicação do braço longo do cromossomo $\mathrm{X}$ e a perda do braço curto.

Existem outros casos raros associados com um $X$ autossomo translocado, deletado ou invertido (LOPEZ et al., 2002) ${ }^{5}$. A incidência é de 1:2.130 nativivas (BALDIN et al., 2005) ${ }^{1}$.

Entretanto, a freqüência real é bem maior porque $99,9 \%$ dos fetos com essa síndrome não sobrevivem a $28^{\circ}$ semana de gestação (LOPEZ et al., 2002)

Em 1986, um estudo realizado na Inglaterra, observou que a expectativa de vida nesta síndrome era menor que a da população geral, sendo menos de 13 anos no primeiro ano de vida, e menos de dez anos quando estas pacientes atingiam quarenta anos (GUIMARÃES et al., 2001)². Em estudo recente Gravholt (1998) sugeriu ocorrer uma diminuição do tempo de vida de portadoras da ST em conseqüência da maior incidência de doenças cardiovasculares, hipertensão e diabetes (GUIMARÃES et al., 2001)².

\section{REVISÃO DE LITERATURA}

Os sinais clínicos para diagnóstico incluem baixa estatura, aproximadamente $20 \mathrm{~cm}$ mais baixas (BALDIN et al., 2005) ${ }^{1}$, disgenesia gonadal, atraso no desenvolvimento puberal, amenorréia primária, esterilidade, linfoedema congênito, tórax proeminente largo e em escudo, peito largo, pescoço curto e/ou alado, cubitus valgus, baixa implantação dos cabelos na nuca, orelhas proeminentes e de implantação baixa, unhas hipoplásicas e hiperconvexas, quarto metacarpo pequeno, face com forma triangular, aumento da distância intermamilar com mamilos hipoplásicos, estrabismo, nevos e múltiplos pigmentados, ptose palpebral, pregas epicânticas. Possuem inteligência normal, somente as meninas que menstruam espontaneamente apresentam retardo mental em maior ou menor gravidade (GUIMARÃES et al., 2001)2. A ST pode estar associada com mal formações cardíacas (principalmente as lesões do "coração esquerdo") e renais (duplicidade do sistema 
coletor, rotação dos rins), deficiência auditiva, hipertensão, doenças tireoideanas, osteoporose, obesidade, diabetes melitus, alopécia, alterações psicológicas e neuropsicológicas, otite média, resistência insulínica, hipercolesterolemia, endocardite, doença celíaca, vitiligo (BALDIN et al., 2005; GUIMARÃES et al., 2001; SUZIGAN, 2005) 1,2,10.

Paciente com Síndrome de Turner apresentam, geralmente, as seguintes alterações: crescimento esqueletal craniofacial desbalanceado, redução da dimensão transversal da maxila e retrusão de ambas as maxilas, alto arco palatal, altas ocorrências de fissuras palatinas, micrognatia, más oclusões (descritas a seguir), erupções dentárias precoces, amontoamento dentário, alterações nas formas dos dentes, tamanho e na espessura do esmalte, reabsorção radicular idiopática. Os "Dentes de Turner" são descritos como dentes permanentes, especialmente os segundos molares inferiores, que apresentam hipoplasia em suas coroas. Gengivites marginais, bolsas periodontais e mobilidade dentária têm sido descritos em adultos com ST (LOPEZ et al., 2002)5. Uma baixa prevalência de cáries dentárias foi observada em dentes permanentes de mulheres com o cariótipo 45,X (LOPEZ et al., $2002)^{5}$. Estudos da morfologia dos dentes em pacientes com a Síndrome de Turner mostraram uma diminuição nas dimensões mesiodistal e bucolingual (KUSIAK, 2005) ${ }^{4}$. Observaram-se, também, anomalias na morfologia das raízes em pacientes com a síndrome de Turner (LOPEZ et al., 2002) ${ }^{5}$.

Kusiak (2005) ${ }^{4}$ relata que as mais freqüentes deformidades são duas raízes nos primeiros e segundos pré-molares inferiores com total desenvolvimento das raízes mesial e distal separada nos ápices.

Outras características foram observadas em apenas algumas pacientes com a presente patologia, como por exemplo: assimetria unilateral, convergência cervicoincisal de faces proximais de incisivos e borda afiada de incisivos superiores. As cúspides palatinas e linguais de caninos são afiadas e de tamanho normal, cúspides atípicas de pré-molares incluindo redução da cúspide lingual dos primeiros pré-molares superiores e pré-molar cônico. Exames radiográficos mostraram uma redução no comprimento das raízes de pré-molares, rotação do primeiro pré-molar superior, agenesia em incisivos, caninos e pré-molares e diastemas (LOPEZ et al., 2002) ${ }^{5}$.

Em um estudo da oclusão em pacientes com ST as características relatadas verificouse, quando comparadas com meninas normais, que o overbite foi significativamente reduzido nas pacientes 45,X. A prevalência de oclusão disto-molar e mordida aberta anterior e lateral e mordida cruzada lateral foi significativamente aumentada (MIDTBO e HALSE, 1996) ${ }^{6}$. Os resultados mostram que pacientes com aberrações estruturais e/ou numéricas do cromossomo $X$ desenvolvem um modelo específico de má oclusão com desvios para sagital, vertical e transversal. O tamanho e a forma da maioria das estruturas craniofaciais são alteradas. A parte posterior da base do crânio é diminuída e o ângulo da base do crânio é aplanado, resultando em uma posição retrognática da mandíbula. A mandíbula é pequena e larga comparada com estreito arco da maxila, a maturação dental é acelerada sendo, também, descritos problemas na erupção (MIDTBO e HALSE, 1996) ${ }^{6}$. Os mesmos autores também relatam que a falta de erupção é uma das causas das anormalidades de mordida aberta.

A dentição não tratada em crianças com síndrome de Turner é caracterizada pelo acelerado desenvolvimento dentário, mas a seqüência de erupção dos dentes não é, significantemente, diferente da população normal (HASS et al., 2001) ${ }^{3}$. Não existe relato de caso em que o hormônio de crescimento 
influencia no tratamento do desenvolvimento dentário em pacientes com Síndrome de Turner. Na baixa estatura desses pacientes e no hipopituitarismo, o tratamento ajuda a normalizar o crescimento do esqueleto, mas - desenvolvimento dentário não é significativamente afetado (PERKIOMAKI et al., 2005) ${ }^{8}$.

Distúrbios endócrinos têm sido associados com o retardo ou falha na erupção. Hipotireoidismo e Hipopituitarismo são os mais freqüentes exemplos encontrados (MIDTBO e HALSE, 1996) ${ }^{6}$.

Crescimento e mecanismos reguladores parecem ser influenciados por genes existentes no cromossomo $\mathrm{X}$, esses genes influenciam no tamanho dos dentes e da maxila. É evidenciado na literatura que fatores hormonais e ambientais também podem contribuir para anormalidades dentárias (LOPEZ et al., 2002) ${ }^{5}$. Defeitos gengivais podem sofrer influencia hormonal e de higiene, pois um aumento sistêmico de hormônios sexuais na presença de placa dental é, também, responsável por processos de doenças periodontais (MIDTBO e HALSE, 1996, citados por LOPEZ et al., 2002) ${ }^{5}$. O planejamento de um tratamento ortodôntico para um paciente com Síndrome de Turner deve ser realizado por uma equipe multidisciplinar, podendo envolver cardiologista, endocrinologista, geneticista e cirurgião-dentista. O cardiologista está associado com algumas anomalias cardiovasculares e a utilização de uma profilaxia antibiótica. Já o endocrinolgista promovendo o crescimento da paciente (RUSSELL, 2001) ${ }^{9}$. Seu tratamento tem como objetivos principais promover o crescimento, repor esteróides sexuais, corrigir, sempre que possível, as anomalias congênitas ou adquiridas, oferecer suporte psicossocial e, conseqüentemente, melhorar a qualidade de vida das pacientes. Desse modo, acreditasse que a presença de tantos sinais e sintomas, bem como a magnitude dos mesmos, pode causar graves conseqüências no funcionamento psicológico e social destes pacientes (SUZIGAN et al., 2005) ${ }^{10}$.

\section{RELATO DE CASO}

Paciente M. C. V. do sexo feminino, cor negra, 18 anos, natural de Ji-Paraná (RO) residente em Campo Largo (PR), compareceu à Disciplina de Semiologia Aplicada do Curso de Odontologia da Universidade Federal do Paraná (UFPR) no dia 23 de agosto de 2006 indicada por uma amiga.

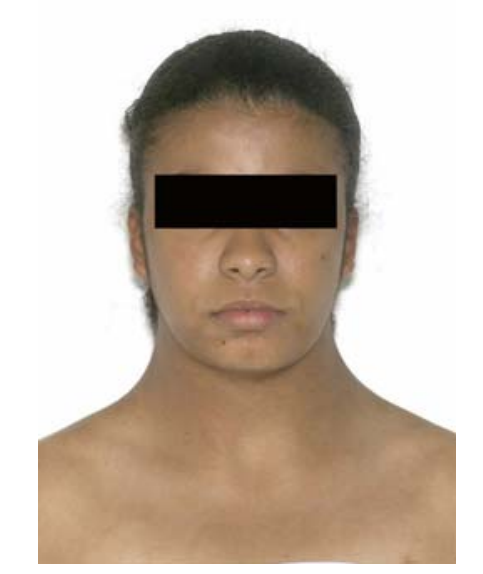

FIGURA 1A - EXAME EXTRA-ORAL

Sua queixa principal era a necessidade de usar aparelho ortodôntico e dúvida sobre a ausência do canino superior esquerdo (23). Durante a anamnese a paciente relatou ter Síndrome de Turner (ST) e já ter realizado uma cirurgia cardíaca e fazer uso de anticoncepcional por razões endocrionológicas. No histórico familiar, os avós maternos morreram de derrame, a mãe (40 anos) sofre de reumatismo e o pai (48 anos) possui varizes no esôfago.

As características físicas e odontológicas observadas na paciente relacionadas à Síndrome de Turner foram a presença de pescoço curto e alado, baixa estatura $(1,47 \mathrm{~m})$, esterilidade, tórax proeminente, baixa implantação dos cabelos na nuca. 

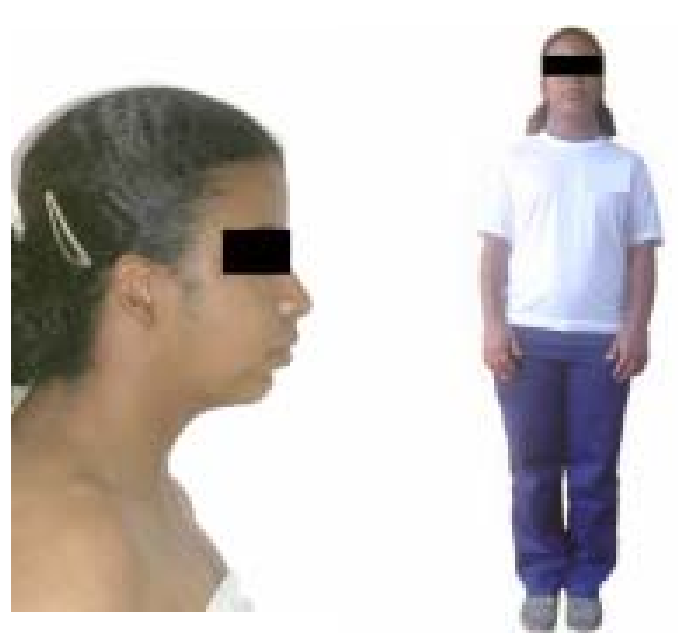

FIGURA 1B - EXAME EXTRA-ORAL

A referida paciente apresenta, inteligência normal, alterações nas formas dos dentes, baixa prevalência de cáries dentárias, diastema nos incisivos centrais superiores devido a baixa implantação do freio, mordida aberta anterior e presença de dente incluso (23).
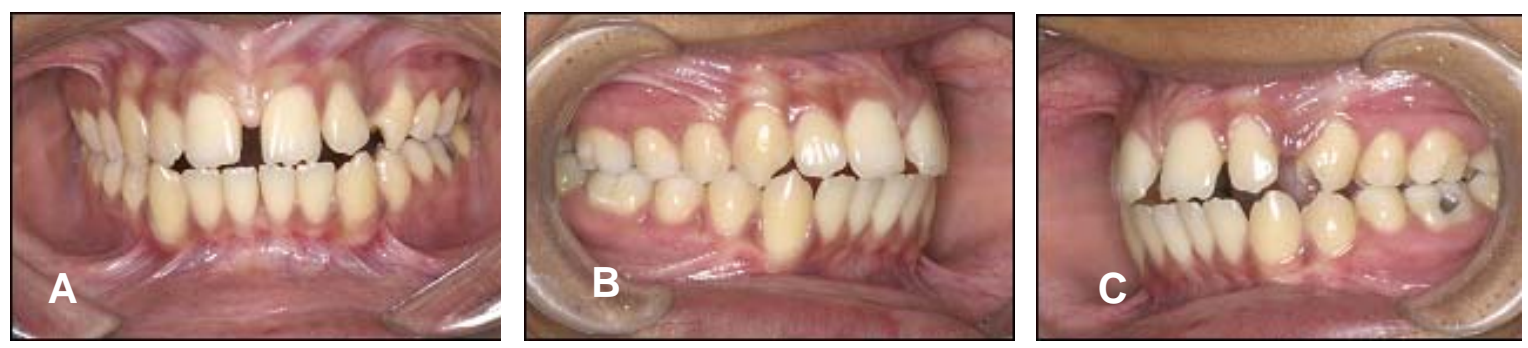

FIGURA 2 - EXAME INTRA-ORAL (MORDIDAS)

Legenda: A - frontal; B - lateral direita; C - lateral esquerda

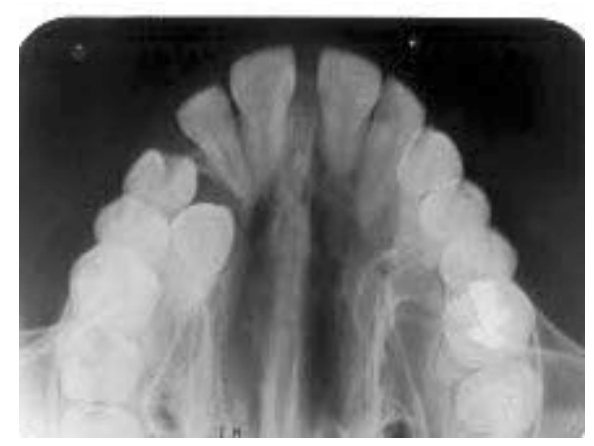

FIGURA 3 - RADIOGRAFIA OCLUSAL DE MAXILA (DENTE INCLUSO)

As características clínicas, no que diz respeito a boca, são presença de manchas raciais melânicas, paciente respiradora bucal e higiene bucal adequada, restaurações nos elementos $16,36,46,47$, selante no 45 e tratamento endodôntico no elemento 47 e oclusão molar Classe I com mordida aberta anterior. 

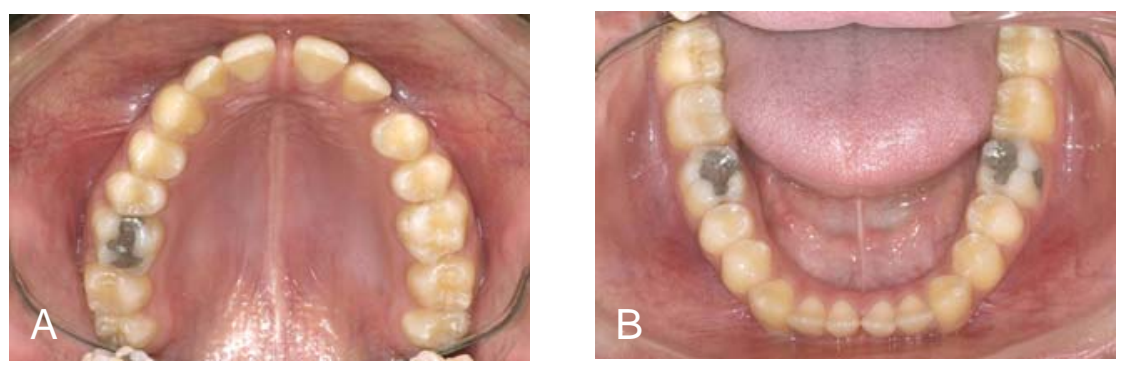

FIGURA 4 - EXAME INTRA-ORAL

Legenda: A - arcada superior; B - arcada inferior

Exames complementares foram realizados como radiografias panorâmicas, $\mathrm{RX}$ oclusal de maxila (para localização de dente incluso) e duas periapicais (região de pré-molares inferiores).

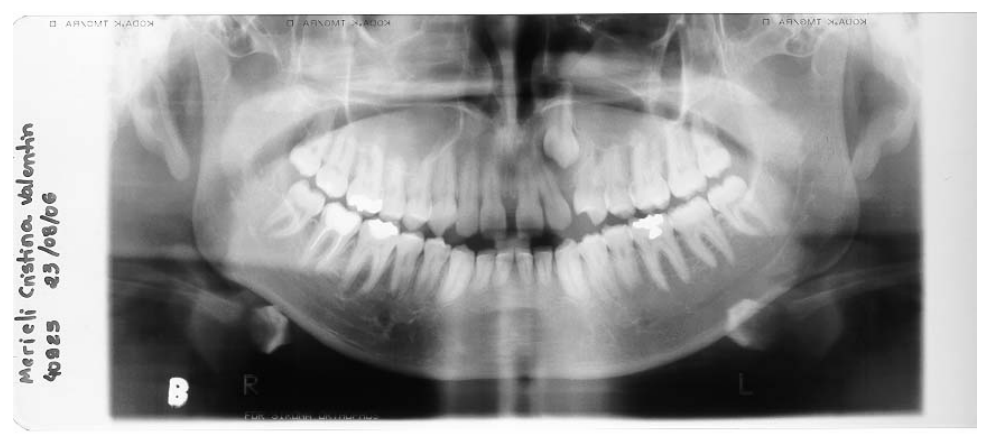

FIGURA 5 - RADIOGRAFIA PANORÂMICA
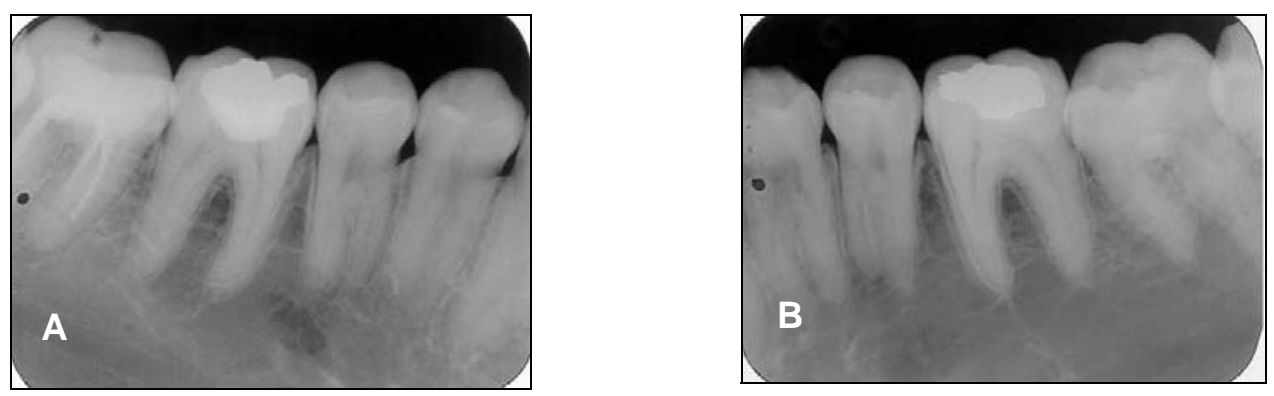

FIGURA 6 - RADIOGRAFIAS PERIAPICAIS PARA AVALIAÇÃO DOS PRÉ-MOLARES 


\section{CONSIDERAÇÕES FINAIS}

Como a Síndrome de Turner possui uma série de anomalias, é relevante que o cirurgiãodentista tenha os conhecimentos básicos de farmacologia, fisiologia, anatomia, genética e patologia para que a partir disso possa atender uma paciente com esta patologia, oferecendoIhe um tratamento que conduza ao melhor prognóstico, por isso é necessário que:

a) realize-se uma prevenção da endocardite bacteriana, uma vez que essa síndrome tem elevados índices de doenças cardiovasculares, prevenção esta realizada com profilaxia antibiótica;

b) em casos de tratamento endodôntico de pré-molares, é necessário que o dentista fique atento, pois há maior incidência de duas raízes e com ápices radiculares separados;

c) haja um acompanhamento metódico e criterioso da saúde bucal desses pacientes, pois em função da utilização de hormônios, necessários à função endócrina, ocorrerá um aumento da placa dental, aumentando com isso a incidência de gengivite e periodontite;

d) haja critério à indicação e ao tratamento ortodôntico destes pacientes.

Através deste relato de caso, o presente trabalho objetivou informar aos profissionais da área de saúde, especialmente os cirurgiões-dentistas, a respeito da importância de uma patologia de ordem sistêmica, e de como a mesma pode interferir nas manifestações clínicas, no tratamento e no prognóstico odontológico. 


\section{REFERÊNCIAS}

1. BALDIN, A. D.; ARMANI, M. C. A.; MORCILLO, A. M.; LEMOS-MARINI, S. H. V.; BAPTISTA, M. T. M.; MACIEL-GUERRA, A. T.; GUERRA JÚNIOR, G. Proporções corporais em um grupo de pacientes brasileiras com Síndrome de Turner. Arquivo Brasileiro de Endocrinologia e Metabolismo, v.49, n.4, p.529-535, ago, 2005.

2. GUIMARÃES, M. M.; GUERRA, C. T. G.; ALVES, S. T. F.; CUNHA, M. C. S. A.; MARINS, L. A.; BARRETO, L. F. M. et al. Intercorrências clínicas na síndrome de Turner. Arquivo Brasileiro de Endocrinologia e Metabolismo, v.45, n.4, p.331338, ago, 2001.

3. HASS, A. D.; SIMMONS, K. E.; DEVENPORT, M. L.; PROFFIT, W.R. The effect of growth hormone on craniofacial growth and dental maturation in Turner syndrome. Angle Orthodontists, v.71, n.1, p.50-59, feb, 2001.

4. KUSIAK, A.; SADLAK, N. J.; LIMON, J.; KOCHANSKA, B. Root morphology of mandibular premolars in 40 patients with Turner syndrome. International Endodontic Journal, v.38, n.22, p.822-826, nov, 2005.

5. LOPEZ, M. E.; BAZAN, C.; LORCA, I. A., CHERVONAGURA, A. Oral and clinical characteristics of a group of patients with Turner síndrome. Oral Surgery, Oral Medicine, Oral Pathology, Oral Radiology, and Endodontology, v.94, n.2, p.196204, aug, 2002.

6. MIDTBO, M.; HALSE, A. Occlusal morphology in Turner syndrome. European Journal of Orthodontics, v.18, n.2, p.103-109, apr, 1996.

7. MIDTBO, M.; WISTH, P. J.; HALSE, A. Craniofacial morphology in young patients with Turner syndrome. European Journal of Orthodontics, v.18, n.3, p.215-225, jun, 1996.

8. PERKIOMAKI, M. R.; KYRKANIDES, S.; NIINIMAA, A.; ALVESALO, L. The relationship of distinct craniofacial features between Turner syndrome females and their parents. European Journal of Orthodontics, v.27, n.1, p.48-52, feb, 2005.

9. RUSELL, K. A. Orthodontic treatment for patients with Turner syndrome. American Journal of Orthodontics Dentofacial Orthopedics, v.120, n.3, p.314-322, sep, 2001.

10. SUZIGAN, L. Z. C.; SILVA, R. B. de P. e; MACIEL-GUERRA, A.T. Aspectos psicossociais da síndrome de Turner. Arquivo Brasileiro de Endocrinologia e Metabolismo, v.49, n.1, p.157-164, jan/fev, 2005.

Marcela Lima Cardoso Selow marcela_amil@yahoo.com.br 